\title{
Penetration force and cannula sliding profiles of different pen needles: the PICASSO study
}

This article was published in the following Dove Press journal:

Medical Devices: Evidence and Research

\author{
Luca Leonardi \\ Mara Viganò' \\ Antonio Nicolucci ${ }^{2}$ \\ 'Pikdare S.p.A., Casnate Con Bernate \\ 22070, CO, Italy; ${ }^{2}$ CORESEARCH, \\ Center for Outcomes Research and \\ Clinical Epidemiology, Pescara $65 / 24$, \\ Italy
}

Correspondence: Luca Leonardi Pikdare Research \& Development, Via F. Catelli, I0, Casnate Con Bernate 22070 , CO, Italy

Tel +3903I 7297111

Fax +390317297100

Email Luca.Leonardi@pikdare.com

\begin{abstract}
Purpose: Pen needles used for insulin injections can have different characteristics that affect a patient's injection experience. The aim of the study was to investigate in a standardized laboratory setting the penetration force and sliding force of different $31 / 32 / 33 / 34$ gauge pen needles available in $3.5 / 4 / 5 / 8 \mathrm{~mm}$ length and $3 / 5$ bevel tips for subcutaneous injection through pen needles and injection pens.

Methods: Eight different commercially available pen needles were tested in this experimental study. The needle was inserted into a polyurethane substrate at a specific constant speed and the force for insertion was recorded as a function of penetration depth. A load cell was utilized to measure force during the different stages of insertion.

Results: Maximum load was lower with the PiC G32×4 when compared with the G32×4 5bevel needle $(p<0.0001)$, while it was not significantly lower with the PiC G32 $\times 4$ when compared to the G32 $\times 4$ 3-bevel needle $(p=0.064)$. The comparison of $\mathrm{G} 33 \times 4 \mathrm{PiC}$ and G34×3.5 PiC needles with G32 needles demonstrated significantly lower maximum loads with G33 and G34 $(p<0.0001)$. No difference between needles emerged for sliding results. Conclusion: Newer pen needles represent a significant improvement in insulin delivery, reducing the amount of force required to penetrate tissues. Needle tip sharpness and other factors that can reduce the force of insertion such as lubrication are important parameters that can be optimized to increase patient acceptance.
\end{abstract}

Keywords: penetration force, maximum load, average sliding

\section{Introduction}

According to the International Diabetes Federation, ${ }^{1}$ some 425 million people worldwide, or $8.8 \%$ of the adults aged 20-79 years are estimated to have diabetes. If these trends continue, 629 million people aged 20-79 years will have diabetes by 2045 . In high-income countries, approximately $87-91 \%$ of all people with diabetes are estimated to have type 2 diabetes, $7-12 \%$ to have type 1 diabetes, and $1-3 \%$ to have other types of diabetes. Globally, diabetes results in USD 727 billion being spent yearly by people with diabetes only on healthcare, which corresponds to one of every eight dollars spent on healthcare. Approximately 4.0 (3.2-5.0) million people aged between 20 and 79 years are estimated to die from diabetes in 2017, which is equivalent to one death every 8 seconds. Diabetes accounted for $10.7 \%$ of the global all-cause mortality among people in this age group. To date, about 150-200 million people require insulin therapy worldwide, ${ }^{2}$ and according to recent research by Stanford University, $^{3}$ insulin use is estimated to increase from 516.1 million $1000 \mathrm{IU}$ vials per year in 2018 to 633.7 million per year in 2030. Insulin is available in 
rapid-, short-, intermediate-, and long-acting types that may be injected separately or mixed in the same syringe. Conventional insulin administration involves subcutaneous injection with syringes marked in insulin units. When insulin was first discovered in the early 1920s, the method of delivery used large glass syringes and reusable needles, both of which needed sterilization by boiling after each use. For over 50 years, vial and syringe remained the only delivery option available for routine clinical use. The first manufactured insulin pen was introduced in $1985,{ }^{4}$ and today several pen-like devices and insulin-containing cartridges are available that deliver insulin subcutaneously through a needle. The original needles for subcutaneous injections were of a much larger diameter (25G) and longer than today's, with a high risk of intramuscular insulin delivery. ${ }^{5}$ Furthermore, although hypodermic needles are effective, the pain, anxiety, needle phobia, and difficulty of use have made them widely unpopular with patients. Consequently, there is poor compliance in initiating and adhering to needle-dependent therapies such as insulin administration. ${ }^{8}$ Manufacturers responded by introducing thinner, shorter, and more accurate pen needles, leading to a reduction in necessary injection force, skin trauma, and pain. ${ }^{6}$ In many patients (e.g., especially those who are neurologically impaired and those using multiple daily injection regimens), these devices have been demonstrated to improve the accuracy of insulin administration and/or adherence. ${ }^{7}$ In addition, more diabetes medications have been recently made available for injection: for example, GLP-1 receptor agonists when given by subcutaneous injection with pen devices, become receptor bound and act similarly to the native hormone. Therefore, there is a medical need to develop less painful needles and more convenient delivery systems. With this purpose, Pikdare has been developing three-bevel needles with improved technical characteristics, namely the primary bevel angle being lower $\left(7.5^{\circ}\right.$ vs $11^{\circ}$ ) than common bevels: this makes the needle tip longer and with a more streamlined shape, thus allowing for a more gradual insertion into skin (Figure 1). The aim of this study was to investigate in a standardized laboratory setting the penetration force and sliding force of different $31 / 32 / 33 / 34$ gauge pen needles available in $3.5 / 4 / 5 / 8 \mathrm{~mm}$ length and $3 / 5$ bevel tips for subcutaneous injection through pen needles and injection pens.

\section{Methods}

Test methodology was based on ISO 7864:2016, annex D. The needle to be tested was inserted into a polyurethane substrate at a specific constant speed and the force for insertion was recorded as a function of penetration depth. A load cell was utilized to measure force during different stages of insertion.

Maximum force was measured by using an Instron universal testing machine (Instron, Norwood, MA), equipped with a $100 \mathrm{~N}$ load cell. As a human skin substitute, we used a PU foil with $0.4 \pm 0.04 \mathrm{~mm}$ thickness and $85^{\circ} \pm 10$ Shore A hardness (MELAB Medizintechnik und Labor GmbH - DE - 71229 Leonberg - Germany). A substrate holder with a circular open penetration area having a nominal diameter of $10 \mathrm{~mm}$ was used.

G31 and G32 needles from major manufacturers were selected for this study since they represent the "gold standard" size for insulin administration. Furthermore, G33 and G34 needles were also tested in the study

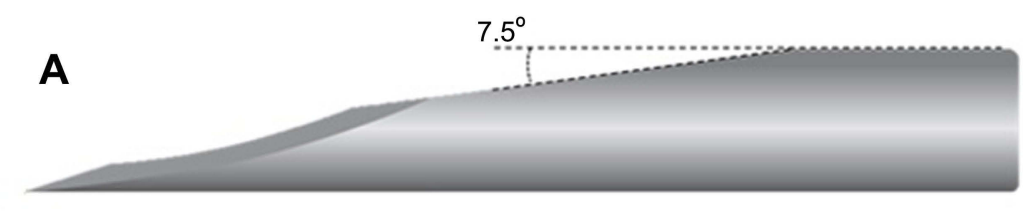

B

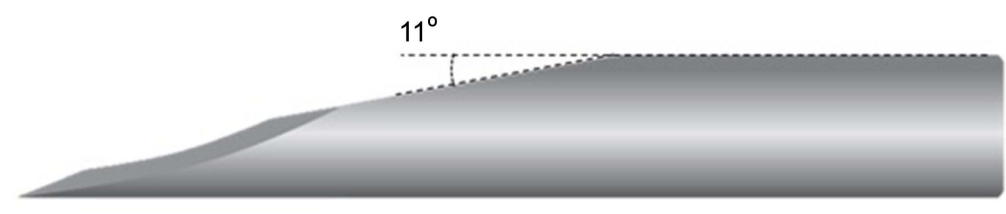

Figure I Tested needles: (A) Pikdare three bevels needle, with a lower primary bevel angle $\left(7.5^{\circ}\right)$ and a more streamlined shape (B) traditional three bevels needle, with a higher primary bevel angle $\left(\mathrm{II}^{\circ}\right)$. 
since they represent a more innovative option available on the market. Products tested included a selection of PiC needles (Pikdare S.p.A.) and needles produced by another manufacturer ( 1 batch per each product, 20 samples per each batch): when the sample size in each of the eight groups is 20, a 0.05 level two-sided $t$-test for independent samples of the specified contrast in a one-way analysis of variance will have $80 \%$ power to detect a Contrast Effect size, $\Delta=|C| /(\sigma)$ of 0.64 .

1. PiC G $32 \times 4$ pen needle

2. G $32 \times 43$-bevel pen needle

3. G $32 \times 45$-bevel pen needle

4. PiC G $33 \times 4$ pen needle

5. PiC G $34 \times 3.5$ pen needle

6. PiC G $31 \times 8$ pen needle

7. G $31 \times 53$-bevel pen needle

8. G $31 \times 5$ 5-bevel pen needle

The PU foil was pierced by the pen needle cannula using the testing machine with a constant speed of $100 \mathrm{~mm} / \mathrm{min}$. The cannula penetration depth into the foil was $8 / 10$ of the cannula length at the patient end. The cannula was inserted into the foil at a $90^{\circ}$ angle. Two values were recorded for each needle tested:

1. Peak penetration force - the maximum force required to insert the needle into the substrate. This force corresponds to the maximum force value in the force profile (in grams).

2. Sliding force - the average "friction" force calculated using up to $80 \%$ of the penetration depth the sliding load (in grams), measured as the average of the whole drag force.

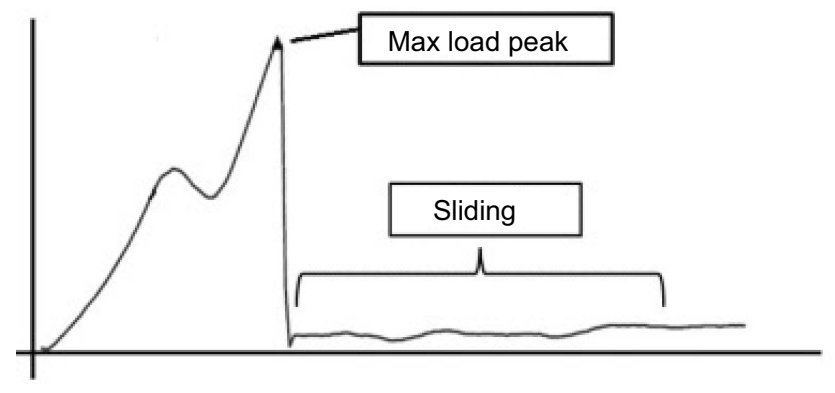

Figure 2 Typical force profile during the penetration of the test foil with a needle, showing the maximum load peak, e.g., the maximum force from the cutting resistance, followed by the sliding of the cannula.
An example of a typical force profile is shown in Figure 2.

Data were analyzed descriptively (mean, standard deviation, 95\% confidence interval, median, min and max values) and graphically with boxplots. In boxplots, the median is identified by a line inside the box; the length of the box is the interquartile range (IQR) computed from Tukey's hinges; values more than three IQRs from the end of a box are labeled as extreme, denoted with an asterisk $(*)$; values more than $1.5 \mathrm{IQRs}$ but less than 3 IQRs from the end of the box are labeled as outliers (o).

Moreover, univariate analysis of variance was applied, estimated marginal means were calculated and Bonferroni adjusted multiple comparisons were made limiting type I errors due to alpha inflation. The statistical software used was IBM SPSS Statistics Version 23.

\section{Results}

Descriptive statistics of max load and average sliding relative to the eight pen needles are presented in Table 1 (n, mean and standard deviation) and in Figures 3 and 4.

Based on maximum load results, as shown in Table 2, PIC G32×4 pen needles were compared to other G32×4 needles. In the first comparison, the maximum load of the PiC G32×4 was lower than with the G32×4 3-bevel needle $(\Delta=4.670)$, but statistical significance was not reached ( $p=0.064$ ). In the second comparison, the maximum load of the PiC G32 $\times 4$ was significantly lower than with the G32 $\times 4$-bevel needle $(\Delta=19.435, p<0.0001)$. The comparison of $\mathrm{G} 33 \times 4 \mathrm{PiC}$ and $\mathrm{G} 34 \times 3.5 \mathrm{PiC}$ needles with $\mathrm{G} 32$ needles demonstrated a lower maximum load with G33 and G34, reaching statistically significant differences $(p<0.0001)$.

Average sliding results were also compared for G32, G33, and G34 pen needles without showing statistically significant differences, therefore with comparable sliding performances among tested needles (Table 3).

Univariate analysis of variance with multiple comparisons has been done also on log-transformed data to satisfy the homoskedasticity and normality of distribution, showing the same results.

\section{Discussion}

A hypodermic needle is typically formed from an elongate tube or cannula having a fluid-conducting lumen and characterized by a central axis. The proximal end of 
Table I Descriptive statistics of maximum load and average sliding by pen needle

\begin{tabular}{|c|c|c|c|}
\hline \multicolumn{3}{|l|}{ Pen needle } & \multirow{3}{*}{$\begin{array}{l}\text { Statistic } \\
53.990 \\
4.2776\end{array}$} \\
\hline \multirow[t]{16}{*}{ Max load (gf) } & \multirow[t]{2}{*}{$\mathrm{G} 32 \times 4 \mathrm{PiC}$} & Mean & \\
\hline & & Std. deviation & \\
\hline & \multirow[t]{2}{*}{ G32×4 3-bevel } & Mean & 58.660 \\
\hline & & Std. deviation & 7.1142 \\
\hline & \multirow[t]{2}{*}{ G32×4 5-bevel } & Mean & 73.425 \\
\hline & & Std. deviation & 7.6463 \\
\hline & \multirow[t]{2}{*}{$\mathrm{G} 33 \times 4 \mathrm{PiC}$} & Mean & 37.880 \\
\hline & & Std. deviation & 2.1598 \\
\hline & \multirow[t]{2}{*}{$\mathrm{G} 34 \times 3.5 \mathrm{PiC}$} & Mean & 36.505 \\
\hline & & Std. deviation & 2.8489 \\
\hline & \multirow[t]{2}{*}{$\mathrm{G} 31 \times 8 \mathrm{PiC}$} & Mean & 52.830 \\
\hline & & Std. deviation & 5.9772 \\
\hline & \multirow[t]{2}{*}{ G31×5 3-bevel } & Mean & 65.260 \\
\hline & & Std. deviation & 3.2464 \\
\hline & \multirow[t]{2}{*}{ G31×5 5-bevel } & Mean & 74.640 \\
\hline & & Std. deviation & 3.6222 \\
\hline \multirow[t]{16}{*}{ Average sliding (gf) } & \multirow[t]{2}{*}{$\mathrm{G} 32 \times 4 \mathrm{PiC}$} & Mean & 4.590 \\
\hline & & Std. deviation & 0.5291 \\
\hline & \multirow[t]{2}{*}{ G32×4 3-bevel } & Mean & 4.455 \\
\hline & & Std. deviation & 1.6240 \\
\hline & \multirow[t]{2}{*}{ G32×4 5-bevel } & Mean & 4.210 \\
\hline & & Std. deviation & 1.5186 \\
\hline & \multirow[t]{2}{*}{$\mathrm{G} 33 \times 4 \mathrm{PiC}$} & Mean & 4.955 \\
\hline & & Std. deviation & 1.1901 \\
\hline & \multirow[t]{2}{*}{$\mathrm{G} 34 \times 3.5 \mathrm{PiC}$} & Mean & 4.255 \\
\hline & & Std. deviation & 0.9757 \\
\hline & \multirow[t]{2}{*}{$\mathrm{G} 31 \times 8 \mathrm{PiC}$} & Mean & 4.110 \\
\hline & & Std. deviation & 0.5937 \\
\hline & \multirow[t]{2}{*}{ G31×5 3-bevel } & Mean & 4.890 \\
\hline & & Std. deviation & 1.4668 \\
\hline & \multirow[t]{2}{*}{ G3I×5 5-bevel } & Mean & 3.010 \\
\hline & & Std. deviation & 1.0848 \\
\hline
\end{tabular}

Abbreviation: gf, gram-force.

the hypodermic needle is typically configured for mating to, or is otherwise affixed to a fluid delivery device such as a hypodermic syringe. The distal end of the hypodermic needle is typically provided with a pointed tip geometry for piercing elastomeric septum and/or a patient's flesh or tissue so as to deliver the medicament held in the syringe. Various aspects merit to be addressed when designing the pointed tip of the hypodermic needle. For instance, one would like to minimize the needle penetration force necessary for urging the pointed tip of the needle through the skin and flesh structure of the patient. It is generally recognized that by reducing needle penetration force, the patient will experience less pain, making the injection more comfortable. Sliding force is also associated with discomfort and/or pain since it is directly related to the friction that the needle cannula exerts on tissue during skin insertion.

The bevel is the angled surface on a shaft of a sharpened tube to form a slanting edge at the needlepoint, facilitating an atraumatic penetration through the human skin: needle tips vary in terms of bevel design, e.g., the number and angularity of the tip facets. The needlepoint, also known as "lancet point," is the sharpest point of any medical needle. ${ }^{10}$

The typical design of a needlepoint frequently presents three-bevel cuts: the primary bevel, which is the surfaced as a result of grinding the tube at a specific angle $\alpha$, and the two-side bevels, which are secondary grind angle $\beta$ on each side of the primary bevel to form the cutting edge and a sharp needlepoint. The bevel length is by definition the longest distance of a bevel, measured from the tip of the needle to the most proximate area of grinding behind the heel. The side bevel length is measured between the juncture of the side bevel, with the outside surface of the angled surface, and the tip of the needle.

For injection delivery devices, important features include needle diameter (gauge), needle length, needle smoothness, and lubrication. Additionally, the sharpness or bluntness of a needle directly affects pain. ${ }^{9}$ To mitigate pain from hypodermic injections, the effect of needle geometry on pain has been investigated in several studies. Needle gauge and the mechanics of needle insertion have been shown to significantly affect pain. ${ }^{11,12}$ The force of hypodermic needle insertion has been found to positively correlate with the frequency of pain. ${ }^{8}$

The results of this study demonstrated that marketed pen needles with similar technical characteristics sometimes show different performances. Remarkably, the PiC G32 $\times 4$ pen needle demonstrated a significantly lower maximum load in comparison with the G32 $\times 4$ 5-bevel pen needle. The comparison of the $\mathrm{G} 33 \times 4 \mathrm{PiC}$ and G34×3.5 PiC needles with the G32 needles demonstrated a significantly lower maximum load with G33 and G34. On the other hand, comparable sliding performances were demonstrated among tested needles. 


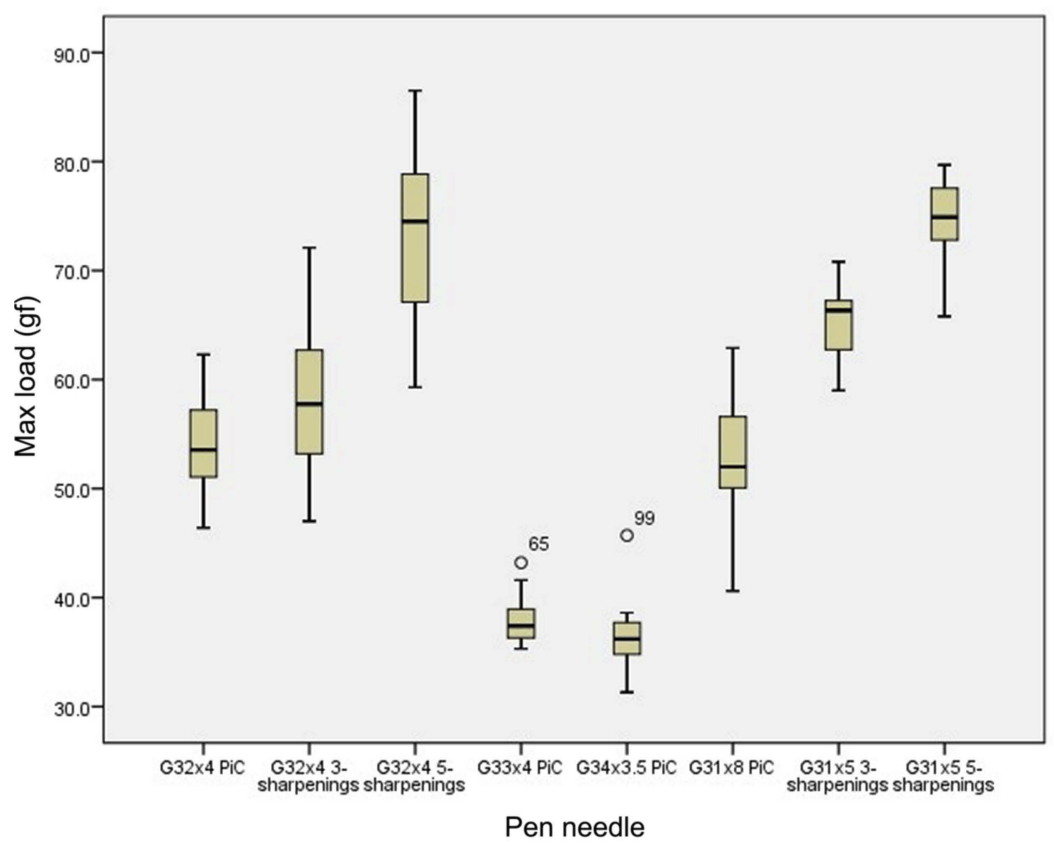

Figure 3 Maximum load by pen needle.

Abbreviation: gf, gram-force.

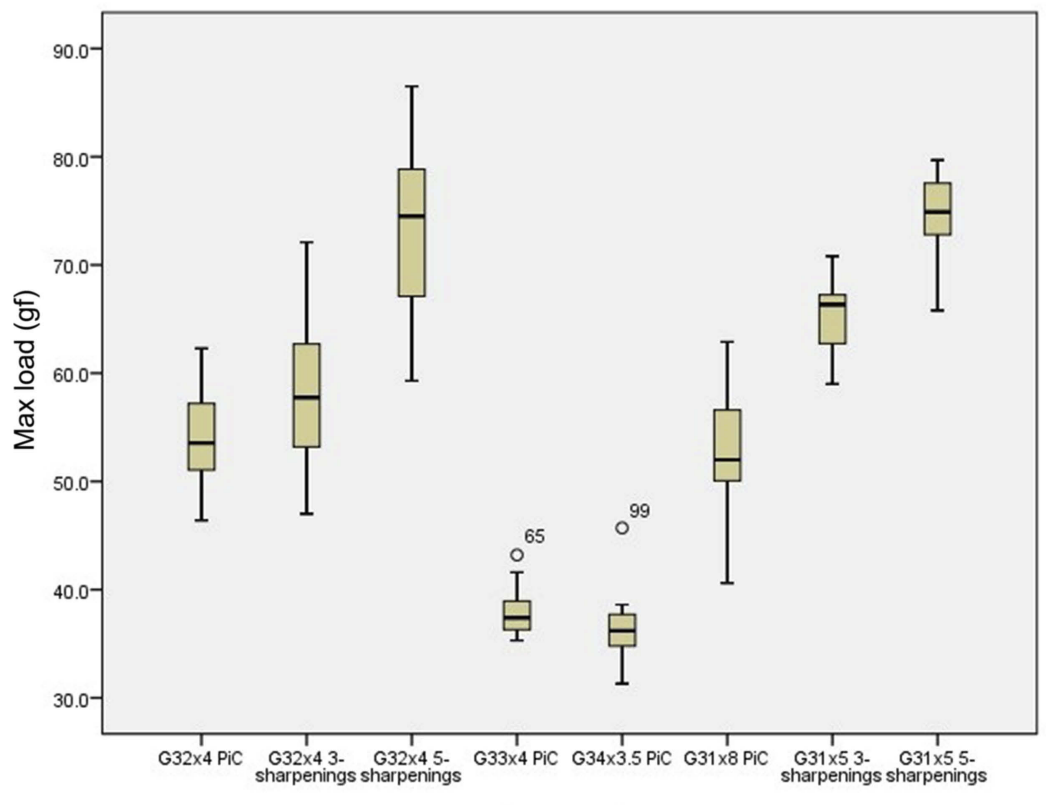

Pen needle

Figure 4 Average sliding by pen needle.

Abbreviation: gf, gram-force.

These data are important for increasing patient and provider awareness of currently available devices for insulin administration.

The main limitation of this study is the laboratory testing of pen needles, which only allows to predict potential benefits for patients.

\section{Conclusion}

Newer pen needles represent a significant improvement in insulin delivery, reducing the amount of force required to penetrate tissues. The force of hypodermic needle insertion has been found to positively correlate with the frequency of pain. ${ }^{8}$ Thus, needle tip sharpness 
Table 2 Pairwise comparison of maximum load of different pen needles evaluated in the study

\begin{tabular}{|c|c|c|c|c|c|c|}
\hline \multirow[t]{2}{*}{ Dependent variable } & \multirow[t]{2}{*}{ (I) Pen needle } & \multirow[t]{2}{*}{ (J) Pen needle } & \multirow[t]{2}{*}{ Mean difference $(I-J)$} & \multirow[t]{2}{*}{$p$-value } & \multicolumn{2}{|c|}{$\begin{array}{l}\text { 95\% Confidence interval for } \\
\text { difference }^{a}\end{array}$} \\
\hline & & & & & Lower bound & Upper bound \\
\hline \multirow[t]{3}{*}{ Max load (gf) } & $\mathrm{G} 32 \times 4 \mathrm{PiC}$ & $\begin{array}{l}\text { G32×4 3-bevel } \\
\text { G32×4 5-bevel }\end{array}$ & $\begin{array}{l}-4.670 \\
-19.435^{*}\end{array}$ & $\begin{array}{l}0.064 \\
0.000\end{array}$ & $\begin{array}{l}-9.482 \\
-24.247\end{array}$ & $\begin{array}{l}0.142 \\
-14.623\end{array}$ \\
\hline & $\mathrm{G} 33 \times 4 \mathrm{PiC}$ & $\begin{array}{l}\mathrm{G} 32 \times 4 \mathrm{PiC} \\
\mathrm{G} 32 \times 4 \text { 3-bevel } \\
\text { G32×4 5-bevel }\end{array}$ & $\begin{array}{l}-16.110 * \\
-20.780 * \\
-35.545^{*}\end{array}$ & $\begin{array}{l}0.000 \\
0.000 \\
0.000\end{array}$ & $\begin{array}{l}-20.922 \\
-25.592 \\
-40.357\end{array}$ & $\begin{array}{l}-11.298 \\
-15.968 \\
-30.733\end{array}$ \\
\hline & $\mathrm{G} 34 \times 3.5 \mathrm{PiC}$ & $\begin{array}{l}\text { G32×4 PiC } \\
\text { G32×4 3-bevel } \\
\text { G32×4 5-bevel }\end{array}$ & $\begin{array}{l}-17.485^{*} \\
-22.155^{*} \\
-36.920^{*}\end{array}$ & $\begin{array}{l}0.000 \\
0.000 \\
0.000\end{array}$ & $\begin{array}{l}-22.297 \\
-26.967 \\
-41.732\end{array}$ & $\begin{array}{l}-12.673 \\
-17.343 \\
-32.108\end{array}$ \\
\hline
\end{tabular}

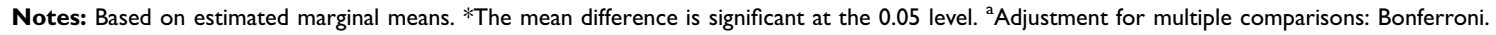
Abbreviation: gf, gram-force.

Table 3 Pairwise comparison of average sliding of different pen needles evaluated in the study

\begin{tabular}{|c|c|c|c|c|c|c|}
\hline Dependent variable & (I) Pen needle & (J) Pen needle & Mean difference $(I-J)$ & $p$-value & \multicolumn{2}{|c|}{$\begin{array}{l}\text { 95\% Confidence interval for } \\
\text { difference }^{a}\end{array}$} \\
\hline Average sliding (gf) & $\mathrm{G} 32 \times 4 \mathrm{PiC}$ & $\begin{array}{l}\text { G32×4 3-bevel } \\
\text { G32×4 5-bevel } \\
\text { G33×4 PiC } \\
\text { G34×3.5 PiC }\end{array}$ & $\begin{array}{l}0.135 \\
0.380 \\
-0.365 \\
0.335\end{array}$ & $\begin{array}{l}1.000 \\
1.000 \\
1.000 \\
1.000\end{array}$ & $\begin{array}{l}-0.985 \\
-0.740 \\
-1.485 \\
-0.785\end{array}$ & $\begin{array}{l}1.255 \\
1.500 \\
0.755 \\
1.455\end{array}$ \\
\hline
\end{tabular}

Notes: Based on estimated marginal means. ${ }^{\text {a} A d j u s t m e n t ~ f o r ~ m u l t i p l e ~ c o m p a r i s o n s: ~ B o n f e r r o n i . ~}$

Abbreviation: gf, gram-force.

and other factors, such as lubrication, which can reduce the force of insertion, are important parameters that can be optimized to increase patient acceptance.

\section{Acknowledgment}

The authors thank Aldo Poli, MD of OPIS Srl, Desio (MB) Italy for statistics/data analysis and Davide Sonnino, MD of OPIS Srl, Desio (MB) Italy for providing medical writing support, which was funded by Pikdare S.p.A., Casnate Con Bernate (CO), Italy.

\section{Disclosure}

Luca Leonardi and Mara Viganò are full-time employees of Pikdare S.p.A. Dr. Antonio Nicolucci reports no conflicts of interest in this work.

\section{References}

1. IDF Diabetes Atlas Eighth edition 2017. Available from: https://diabe tesatlas.org/resources/2017-atlas.html. Accessed August 2, 2019.
2. Garg SK, Rewers AH, Akturk HK. Ever-increasing insulin-requiring patients globally. Diabetes Technol Ther. 2018;20(S2):S21-S24. doi:10.1089/dia.2018.0101

3. Basu S, Yudkin JS, Kehlenbrink S, et al. Estimation of global insulin use for type 2 diabetes, 2018-30: a microsimulation analysis. Lancet Diabetes Endocrinol. 2019;7(1):25-33. doi:10.1016/S2213-8587(18) 30303-6

4. Selam J-L. Evolution of diabetes insulin delivery devices. J Diabetes Sci Technol. 2010;4(3):505-513. doi:10.1177/193229681000400302

5. Frid A, Linden B. Where do lean diabetics inject their insulin? A study using computed tomography. BMJ. 1986;292:1638. doi:10.1136/bmj.292.6536.1638

6. Magwire ML. Addressing barriers to insulin therapy: the role of insulin pens. Am J Ther. 2011;18(5):392-402. doi:10.1097/MJT.0b0 13e3181ef4dde

7. American Diabetes Association. Insulin administration. Diabetes Care. 2003;26(Suppl 1):S121-S124. doi:10.2337/diacare.26.2007. s121

8. Gill HS, Prausnitz MR. Does needle size matter? J Diabetes Sci Technol. 2007;1(5):725-729. doi:10.1177/193229680700100517

9. Hirsch L, Gibney M, Berube J, Manocchio J. Impact of a modified needle tip geometry on penetration force as well as acceptability, preference, and perceived pain in subjects with diabetes. J Diabetes Sci Technol. 2012;6(2):328-335. doi:10.1177/193229681200600216

10. Meyer CH, Kaymak H, Liu Z, Saxena S, Rodrigues EB. Geometry, penetration force, and cutting profile of different 23-gauge trocars systems for pars plana vitrectomy. Retina. 2014;34(11):2290-2299. doi:10.1097/IAE.0000000000000221 
11. Arendt-Nielsen L, Egekvist H, Bjerring P. Pain following controlled cutaneous insertion of needles with different diameters. Somatosens Mot Res. 2006;23(1-2):37-43. doi:10.1080/08990220600700925
12. Egekvist $H$, Bjerring $P$, Arendt-Nielsen L. Pain and mechanical injury of human skin following needle insertions. Eur J Pain. 1999;3(1):4149. doi:10.1053/eujp.1998.0099

\section{Publish your work in this journal}

Medical Devices: Evidence and Research is an international, peerreviewed, open access journal that focuses on the evidence, technology, research, and expert opinion supporting the use and application of medical devices in the diagnosis, monitoring, treatment and management of clinical conditions and physiological processes. The identification of novel devices and optimal use of existing devices which will lead to improved clinical outcomes and more effective patient management and safety is a key feature of the journal. The manuscript management system is completely online and includes a very quick and fair peer-review system. Visit http:// www.dovepress.com/testimonials.php to read real quotes from published authors. 